\title{
English and Black Walnut Phenolic Antioxidant Activity in Vitro and Following Human Nut Consumption
}

\author{
Jacki M. Rorabaugh ${ }^{1}$, Ajay P. Singh ${ }^{2,3}$, Isabel M. Sherrell ${ }^{3}$, Michelle R. Freeman ${ }^{1}$, Nicholi Vorsa ${ }^{2,3}$, \\ Peter Fitschen ${ }^{4}$, Christopher Malone ${ }^{5}$, Margaret A. Maher ${ }^{4}$, Ted Wilson ${ }^{1}$ \\ ${ }^{1}$ Department of Biology, Winona State University, Winona, USA; ${ }^{2}$ Philip E. Marucci Center for Blueberry and Cranberry Research and \\ Extension, Chatsworth, USA; ${ }^{3}$ Department of Plant Biology and Pathology, Rutgers University, New Brunswick, USA; ${ }^{4}$ Department of \\ Biology, University of Wisconsin-La Crosse, La Crosse, USA; ${ }^{5}$ Department of Math and Statistics, Winona State University, Winona, USA. \\ Email: ewilson@winona.edu
}

Received March 1 ${ }^{\text {st }}, 2011$; Revised April 15 ${ }^{\text {th }}, 2011$; Accepted April 23 ${ }^{\text {rd }}, 2011$.

\begin{abstract}
Background: Walnut consumption may reduce the risk of cardiovascular disease by providing antioxidant protection to low density lipoproteins $(L D L)$. Aim: This study compared the phenolic profile and antioxidant activity of English versus black walnuts. Methods: Nuts were extracted in methanol or acetone prior to analysis with HPLC/LC-MS-MS for phenolic identification and quantitation. The ability to prevent oxidation of LDL was examined in vitro using walnut extracts and ex vivo after walnut consumption for 28 days. Results: Flavonoids identified/quantified with HPLC/LCMS-MS included the phenolic acids 5-caffeoylquinic acid, 3-caffeoylquinic acid (black walnut only), 4-caffeoylquinic acid, and the flavonol glycosides quercetin-3-rutinoside, quercetin-3-galactoside, quercetin-3-pentoside, quercetin-3arabinoside, quercetin-3-rhamnoside, and the aglycone quercetin (English walnut only). Total phenolic yield of acetone extracts were 166.1 and $24.2 \mu \mathrm{g} / \mathrm{g}$ for English and black walnut respectively, and yield for methanol extracts were 147.6 and $4.1 \mu \mathrm{g} / \mathrm{g}$ for English and black walnut respectively. In vitro $\mathrm{LDL}$ oxidation by $\mathrm{Cu}^{++}$with English walnut extracts significantly extended oxidation lag-time $\left(A_{234}\right)$ in a dose dependent manner at 1.0 and $0.1 \mu \mathrm{g} / \mathrm{ml}$ and reduced TBARS formation $(1.0 \mu \mathrm{g} / \mathrm{ml})$. Black walnut extracts reduced TBARS significantly but had no effect on $A_{234}$. Human consumption of English or black walnuts (30 $\mathrm{g}$ nuts/day) for 28 days resulted in no differences in LDL antioxidant capacity $\left(A_{234}\right)$ between groups or within groups. Conclusions: This study suggests that the English walnuts have a phenolic profile and in vitro antioxidant capacity that is better than black walnuts, but that walnut consumption for 28 days does not improve $L D L$ resistance to oxidation.
\end{abstract}

Keywords: Walnut, Lipoprotein, Oxidation, Antioxidant, Phenolic, Flavonol

\section{Introduction}

Nut consumption has been demonstrated to be protective against cardiovascular disease, an effect attributable to their phenolic [1], antioxidant [2] and polyunsaturated fat [3]. Walnuts are an important dietary item. In 2008, global total walnut production was estimated to be in excess of 2.1 million metric tons [4]. English walnuts (Juglans regia) and the increasingly popular, black walnuts (Juglans nigra) are currently part of the American diet, with black walnuts having a slightly bitter taste relative to English walnuts. Black walnut trees are native to the United States and grow east of the Rocky Mountains.
English walnut trees are introduced to the United States, with production under cultivation, and cannot survive the temperate American climate without grafting onto black walnut tree roots [5]. English walnuts are known to contain non-flavonoid phenolics in the ellagitannin family including ellagic acid, valoneic acid dilactone, and pedunculagin [6-11], with Anderson et al. 2001 identifying only a single $433 \mathrm{MW}$ flavonol pentoside [9]. The comprehensive profile of flavonol-glycosides in walnuts has not been fully reported or quantified, although their presence in English walnut leaf has been reported and quantified [12].

English walnuts have been reported to be an excellent 
source of antioxidants $[1,9,13]$. Walnut consumption has been shown to be associated with improvements in blood lipid profile [14], possibly by causing changes in HMGCoA activity [15], an observation in agreement with our previous study [16]. Walnuts have also been shown to improve endothelium mediated vasodilation in dyslipidemic subjects following intake of a high fat meal $[16,17]$ and type 2 diabetics [18].

No direct comparisons between English and black walnut phenolic profiles, and their relative in vitro or ex vivo antioxidant activities, have been performed. The present study compared the flavonol-glycoside profiles of English and black walnuts with high-pressure liquid chromatography and liquid chromatography-mass spectroscop-mass spectroscopy (LC-MS-MS) for quantification, and identification. The relative capacities of English and black walnuts to inhibit LDL oxidation were examined using walnut phenolic extracts prepared with acetone or methanol in vitro. Human LDL antioxidant capacity was also examined ex vivo following 28 days of walnut consumption. These comparisons sought to determine if black walnuts would provide comparable health benefits to that of English walnuts. The black walnut, being adapted to more severe temperate climate, would provide an alternative walnut to the intensively cultivated English walnut.

\section{Methods}

Human Studies: This study was approved by the Institutional Review Boards of the University of Wisconsin-La Crosse and Winona State University. All participants read and signed an informed consent document prior to volunteering to participate in this study.

Walnut source and preparation: Black walnuts were obtained through donations from Hammons Products Company (Stockton, MO), Michael Winfrey (Ettrick, WI), and Harry Lundstrom (Unionville, VA). English walnuts were purchased from the People's Food Coop (La Crosse, WI). Walnuts ( $30 \mathrm{~g}$ portions) consisting of nut flesh with attached pellicle were frozen until phenolic extraction or human consumption.

Walnut phenolic extraction: English and black walnut flesh with the kernel and attached pellicle was ground into a course powder with a mortar and pestle. A $5 \mathrm{~g}$ portion of the powder was extracted twice using either $80 \%$ acetone or $80 \%$ methanol in water, followed by centrifugation and supernatant concentration using a rotary evaporator $\left(45^{\circ} \mathrm{C}\right.$ under reduced pressure). Flavonols were isolated from the $80 \%$ acetone and $80 \%$ methanol extracts with Sep Pack C18 cartridges (5 g, Waters Inc., Milford, MA) preconditioned by sequential treatment with $20 \mathrm{~mL}$ of methanol, $20 \mathrm{~mL}$ of $\mathrm{H}_{2} \mathrm{O}$, respectively, under vacuum. The sample solutions were then distributed onto cartridges ( $0.5 \mathrm{~mL}$ per cartridge). Flavonols were removed from cartridges by elution with $20 \mathrm{~mL}$ of methanol followed by water. The eluted methanol solution was concentrated and diluted with HPLC mobile phase-B ( $2 \mathrm{~mL})$ for HPLC and LC-MS-MS analysis as described below. The acetone and methanol extracts were then diluted in phosphate buffered saline for evaluation of their antioxidant capacity as described later.

Walnut Phenolic isolation, identification and quantification: Extract constituents were preparatively isolated using HPLC (Dionex Inc., Sunnyvale, CA) equipped with a UV-Vis PDA 100 Photodiode Array Detector, AS 50 autosampler and GP 40 gradient pump. Mobile phase: Eluent A: $90 \%$ water $+10 \%$ methanol $+0.001 \%$ formic acid; Eluent B: $20 \%$ water $+20 \%$ methanol $+60 \%$ ACN $+0.001 \%$ formic acid. Flow rate: $0.25 \mathrm{~mL} \cdot \mathrm{min}^{-1}$ and injection volume: $5 \mu \mathrm{L}$ for LC-MS-MS. Column: Pursuit C18 $(3 \mu \mathrm{m}$ particle size; $150 \mathrm{~mm}$ length $\times 3.0 \mathrm{~mm}$ ID; Varian Inc, Palo Alto, CA).

Flavonols were identified and quantified by high performance liquid chromatography performed on an API 3000 triple quadrupole mass spectrometer (PE Sciex, Concord, Ontario, Canada). All the analyses were performed using the Electrospray chemical ionization source (ESI) in negative ion mode with the following settings: ion spray voltage $-4200 \mathrm{~V}$, nebulizer gas (N2) 7 (arbitrary units), curtain gas (N2) 12 (arbitrary units), collision gas (N2) 6 (arbitrary units), declustering potential (DP) between $-60 \mathrm{~V}$ to $-100 \mathrm{~V}$, focusing potential $-400 \mathrm{~V}$, entrance potential $-10 \mathrm{~V}$, collision energy $(\mathrm{CE})-50 \mathrm{~V}$ and collision cell exit potential (CXP) $-5 \mathrm{~V}$. The drying gas (N2) was heated to $350^{\circ} \mathrm{C}$ and introduced at a flow rate of $6000 \mathrm{~cm}^{3} \cdot \mathrm{min}^{-1}$. Full scan data acquisition was performed scanning from m/z $100-1200$ in profile mode, using a cycle time of $2 \mathrm{~s}$ with a step size of $\mathrm{m} / \mathrm{z} 0.1$ and an interscan pause of $2 \mathrm{~ms}$.

Identified flavonols were quantified using an HPLC equipped with a Waters 996 Photodiode Array Detector (PDA) (Waters, Milford, MA). Quantification of all the phenolic acids was based on a standard curve prepared with 5-caffeoylquinic acid. Quercetin-3-rutinoside, quercetin-3-galactoside, quercetin-3-rhamnoside and quercetin were quantified using the corresponding authentic standard for each compound. Other flavonols were quantified based on a standard curve of quercetin-3-rhamnoside. For all the standards and extracts, $40 \mu \mathrm{L}$ were injected and separated using the aforementioned column and solvent system, but at a flow rate of $1 \mathrm{~mL} / \mathrm{min}$. Scanning by the PDA occurred at $325 \mathrm{~nm}$ for phenolics and $366 \mathrm{~nm}$ for flavonols, while data acquisition and processing were performed by Waters Empower ${ }^{\mathrm{TM}}$ Chromatography Software (Waters, Milford, MA).

In vitro evaluation of walnut antioxidant capacity: Venous blood was collected in $\mathrm{K}_{3}$ EDTA from three 
healthy adults following a 12 hour abstinence from all food and beverages except water. Plasma LDL was sequentially isolated sequential ultracentrifugation, dialyzed twice in phosphate buffered saline to remove EDTA, and purged with $\mathrm{N}_{2}$ gas to prevent oxidation prior to use within three weeks of collection. LDL isolates were merged and the LDL protein concentration determined with the BioRad DC Protein Assay (Hercules, CA) for use in antioxidant assessment [19].

English and black walnut extract antioxidant capacities were determined in vitro by inducing the oxidation of 100 $\mu \mathrm{g}$ LDL protein $/ \mathrm{mL}$, with 1.00 or $0.10 \mu \mathrm{g} / \mathrm{mL}$ walnut extracts in the presence of $5 \mu \mathrm{M} \mathrm{Cu}^{++}$and measuring conjugated diene formation at $234 \mathrm{~nm}$. The assay was held at a constant temperature of $37^{\circ} \mathrm{C}$ with absorption readings were taken every 85 seconds (300 recordings). Each experiment was performed in triplicate and lag time was determined by finding the midpoint of the resultant curves [19].

The thiobarbituric acid reactive substances (TBARS) assay was performed as a secondary proof that conjugated dienes measured in the $\mathrm{Cu}++$ assay resulted from LDL oxidation. Oxidation was initiated with cupric sulfate (5 $\mu \mathrm{M})$ and $100 \mu \mathrm{g}$ LDL protein $/ \mathrm{mL}$ in PBS incubated at $37^{\circ} \mathrm{C}$ for 95 minutes in the presence or absence of 0.1 $\mu \mathrm{g} / \mathrm{mL}$ walnut extracts. The TBARS test measured malondialdehyde oxidation products using tetramethoxypropane (TMPP, $8 \mathrm{ng} / 100-\mu \mathrm{L}$ incubate) as a standard [20].

Human walnut consumption and antioxidant capacity: Ex vivo antioxidant effects of walnuts were observed in 36 subjects randomly assigned to consume either $30 \mathrm{~g}$ portions of English or black walnuts each day for
28 days, in addition to their usual diet. Fasting venous blood was drawn pre-study (day 0) and day 28. Collected plasma was stored at $-80^{\circ} \mathrm{C}$ with $0.6 \%$ sucrose for stabilization until simultaneous LDL isolation was performed on a single day using sequential ultracentrifugation for day-0 and day-28 samples as describe previously in this manuscript and used within three days of preparation. The antioxidant capacity of each subjects LDL pre- and post walnut consumption was determined by inducing oxidation of $100 \mu \mathrm{g} / \mathrm{mL}$ LDL in the presence of 10,4 , and $1 \mu \mathrm{M}$ cupric ions and measuring conjugated diene formation at $\mathrm{A}_{234}$ as described previously in this manuscript.

Statistical analysis: The data are expressed as means \pm standard deviation. ANOVA was used to determine if the variable interaction in the LDL assay and TBARS was significant. Dunnet's Multiple Comparison procedure was used to compare the extract treatments to the control (LDL with no extract lag-time). Tukey HSD was used to statistically represent the relationship of the extract solvent and concentration used in LDL oxidation. ANOVA and a repeated measures analysis of variance was used to identify significant differences among treatments, time, and interaction between treatment and time. Significant differences among least squares means $(\mathrm{P}<0.05)$ were determined using the Tukey-Kramer adjustment (SAS Inst. Inc., Cary, NC).

\section{Results}

The phenolic acid and flavonol profiles of the identified English and black walnuts were obtained and compounds quantified (Figure 1, Table 1). Phenolics in both $80 \%$ acetone and methanol extracts included phenolic acids

Table 1. Quantitative characterization of English and black walnut flavonol profiles with HPLC and LC-MS-MS.

\begin{tabular}{|c|c|c|c|c|c|c|}
\hline Name of compound & $\lambda_{\max }(\mathrm{nm})$ & $\begin{array}{c}{[\mathrm{M}-\mathrm{H}] \text { fragments in }} \\
\text { ESI-MS }\end{array}$ & $\begin{array}{c}\text { English } \\
80 \% \text { acetone } \\
(\mu \mathrm{g} / \mathrm{g} \text { wet } w \mathrm{t})\end{array}$ & $\begin{array}{c}\text { English } \\
80 \% \text { methanol } \\
(\mu \mathrm{g} / \mathrm{g} \text { wet wt) }\end{array}$ & $\begin{array}{c}\text { Black } \\
80 \% \text { acetone } \\
(\mu \mathrm{g} / \mathrm{g} \text { wet wt) }\end{array}$ & $\begin{array}{c}\text { Black } \\
80 \% \text { methanol } \\
(\mu \mathrm{g} / \mathrm{g} \text { wet wt) }\end{array}$ \\
\hline 3-caffeoylquinic acid & $218,236,293,317$ & $353,191,179,127,111$ & ND & ND & 0.67 & 1.05 \\
\hline 5-caffeoylquinic acid ${ }^{\mathrm{a}, \mathrm{b}, \mathrm{c}}$ & $217,242,298,326$ & $353,191,179,127,111$ & 20.43 & 17.37 & 0.19 & 2.20 \\
\hline 4-caffeoylquinic acid ${ }^{a, b, c}$ & $218,243,297,327$ & $353,191,173,127,111$ & 2.03 & 2.93 & 0.23 & ND \\
\hline Quercetin-3-rutinoside ${ }^{\mathrm{a}, \mathrm{b}, \mathrm{c}}$ & $200,251,351$ & 609,301 & 5.37 & 0.64 & 0.24 & ND \\
\hline Quercetin-3-galactoside ${ }^{a, b, c}$ & $203,254,351$ & 463,301 & 55.63 & 0.33 & 1.39 & 0.05 \\
\hline Quercetin-3-pentoside ${ }^{a, b, c}$ & $204,253,355$ & 433,301 & 71.33 & 78.74 & 21.14 & 0.21 \\
\hline Quercetin-3-arabinoside ${ }^{a, b, c}$ & $204,253,355$ & 433,301 & 0.45 & 39.79 & 0.09 & 0.44 \\
\hline Quercetin $^{\mathrm{a}, \mathrm{b}, \mathrm{c}}$ & $207,266,357$ & 301,151 & 10.21 & 7.70 & ND & ND \\
\hline \multicolumn{3}{|c|}{ Total Phenolics (sum of flavonol constituents; $\mu \mathrm{g} / \mathrm{g}$ ) } & 166.12 & 147.59 & 24.18 & 4.09 \\
\hline
\end{tabular}

ND: Not detected; ${ }^{\mathrm{a}}$ Based on full scan and product ion scan; ${ }^{\mathrm{b}}$ Based on Singh et al. 2009. 

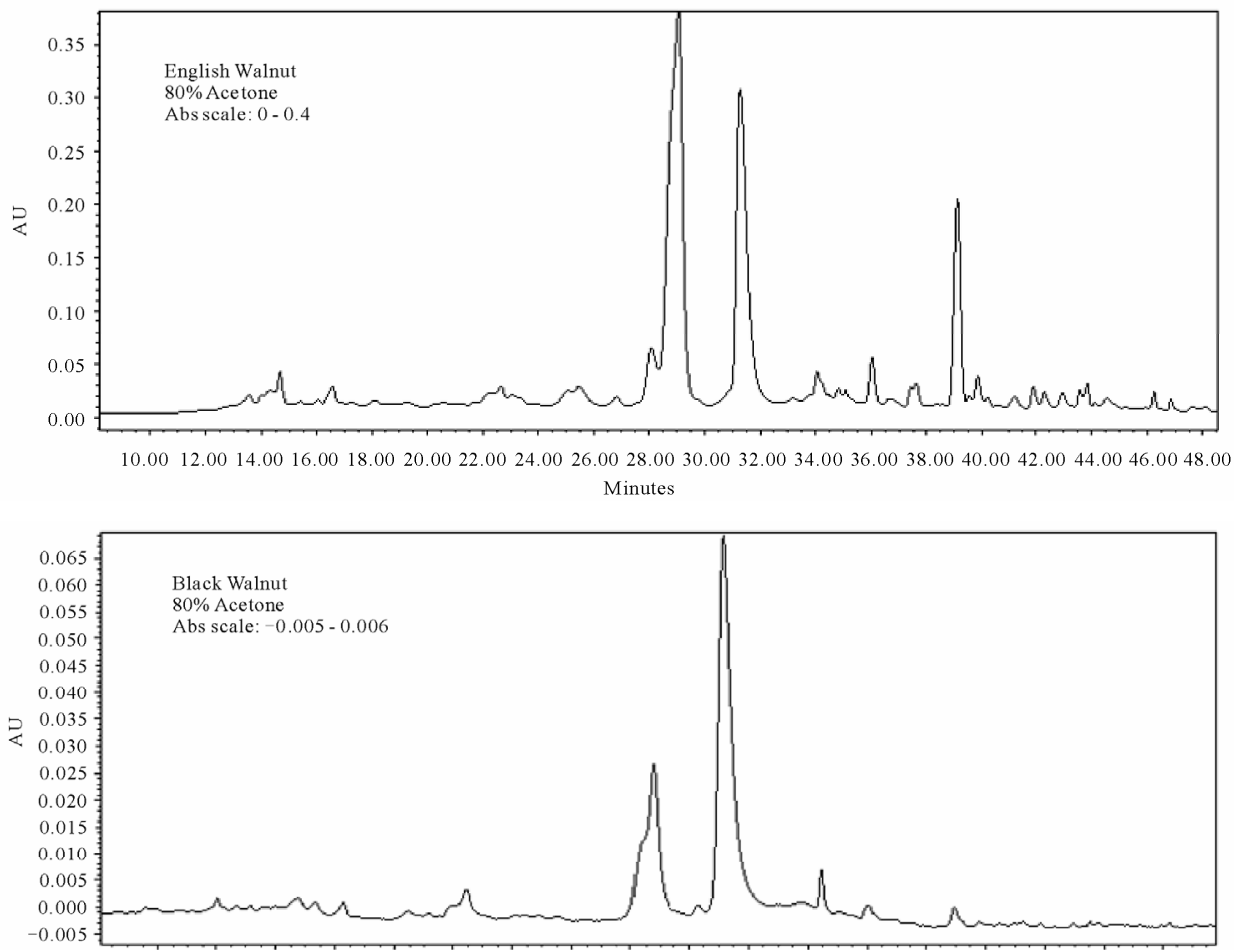

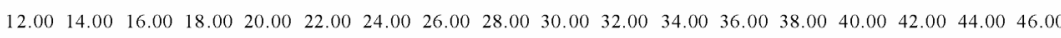
Minutes
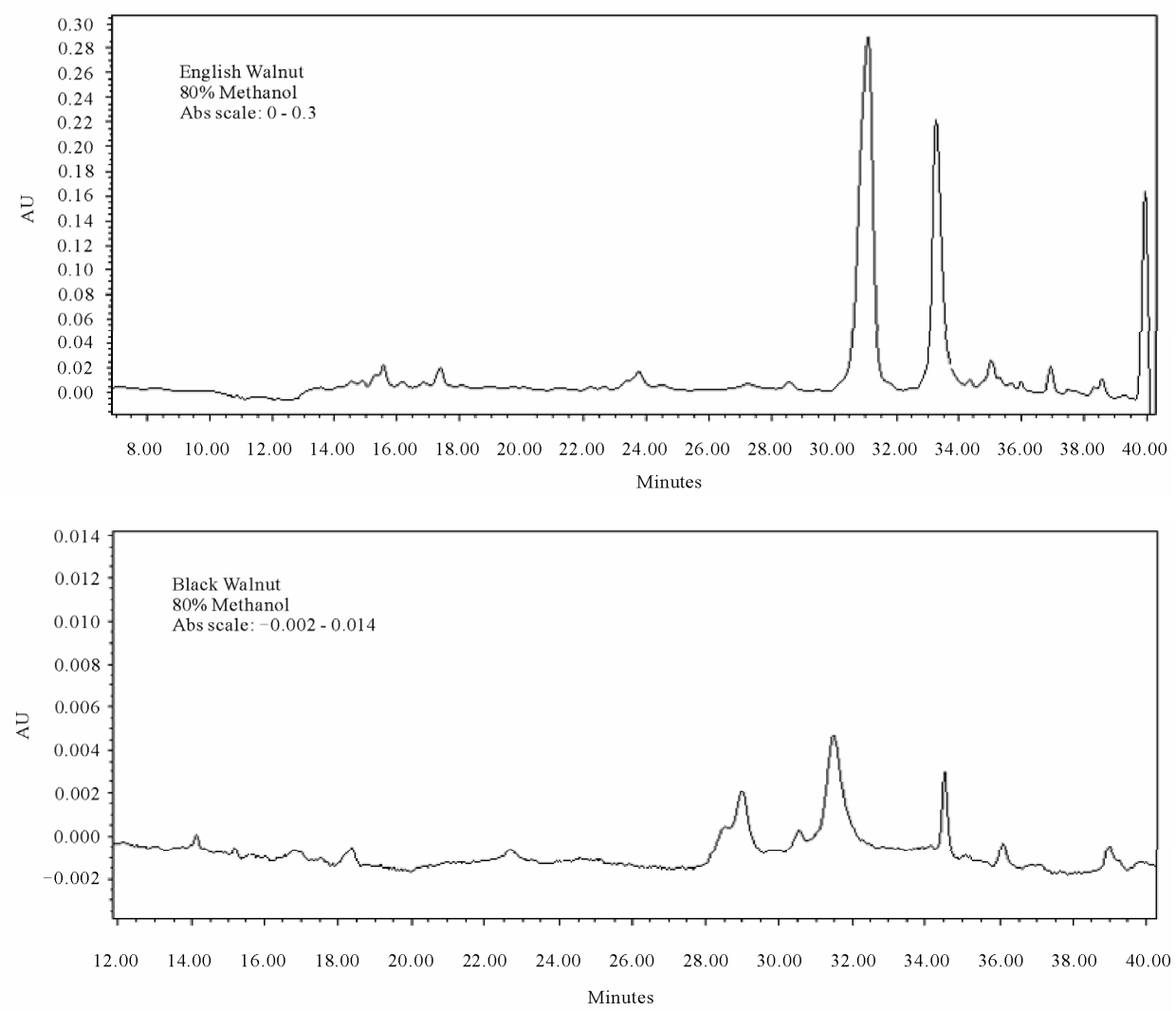

Figure 1. Representative HPLC chromatographs of English and black walnuts extracted with $80 \%$ acetone and $\mathbf{8 0} \%$ methanol demonstrate that English cultivars contain a greater profile of phenolic compounds. 
5-caffeoylquinic acid, 3-caffeoylquinic acid (black walnut only), 4-caffeoylquinic acid, and the flavonols quercetin-3rutinoside, quercetin-3-galactoside, quercetin-3-pentoside, quercetin-3-arabinoside, quercetin-3-rhamnoside, and the aglycone quercetin (English walnut only). Total flavonol yield for the acetone extract was 166.1 and $24.2 \mu \mathrm{g} / \mathrm{g}$ for English and black walnut, respectively, and total yield for the methanol extract was 147.6 and $4.1 \mu \mathrm{g} / \mathrm{g}$ for English and black walnut, respectively.

In vitro $\mathrm{LDL}$ oxidation induced by $\mathrm{Cu}^{++}$(lag-time at $\mathrm{A}_{234}$ ) was significantly inhibited by English walnut extract relative to control LDL, which was oxidized in the absence of acetone or methanol English walnut extracts. The $1.0 \mu \mathrm{g} / \mathrm{mL}$ dose was significantly better than the 0.1 $\mu \mathrm{g} / \mathrm{mL}$ dose of English walnut extract (Figure 2 and 3) for inhibition of oxidation. In contrast, black walnut extracts provided no significant increase in oxidative lag-time and therefore no apparent antioxidant protection of LDL.

In vitro LDL malondialdehyde production was measured with a TBARS assay and supports the results of the oxidative lag-time assay. After 95 minutes of oxidative incubation, TBARS ( $8 \mathrm{ng} \mathrm{TMPP} / 100-\mu \mathrm{L}$ incubate) were $0.76 \pm 0.01$ for control LDL oxidized in the absence of walnut extracts. English walnut acetone and methanol extract TBARS were $0.03 \pm 0.001$ and $0.003 \pm 0.001$ (significant vs control LDL; $\mathrm{p}<0.001$ ), indicative of antioxidant activity. For black walnut acetone and methanol extracts TBARS were $0.63 \pm 0.001$ and $0.63 \pm 0.02$ (significant verses control LDL; $\mathrm{p}<0.001$ ). The English walnut extracts provided significantly lower TBARS and better antioxidant protection than did the black walnut extracts $(\mathrm{p}<0.05)$.

Ex Vivo effects of walnut consumption on human LDL antioxidant capacity before and after consumption of $30 \mathrm{~g}$ nut flesh/day for 28 days was evaluated following oxidation with 10,4 , and $1 \mu \mathrm{M} \mathrm{Cu}^{++}$. There was a slight increase in LDL oxidative lag-time following oxidation by $10 \mu \mathrm{M} \mathrm{Cu++}$, however, no statistically significant changes in LDL oxidation were observed pre- to post-walnut consumption within or between treatment groups. Percent change in LDL lag-time after 28 days of English walnut consumption and oxidation by 10,4 and $1 \mu \mathrm{M}$ cupric sulfate was $-0.09 \pm 0.08,0.13 \pm 0.08$, and $-0.09 \pm 0.08$, respectively. Percent change in LDL lag-time after 28 days of black walnut consumption and oxidation by 10,4 and $1 \mu \mathrm{M}$ cupric sulfate was $-0.11 \pm 0.08,-0.03 \pm 0.08$, and $-0.03 \pm 0.08$, respectively.

\section{Discussion}

This is the first study to compare the identity and quantity of the wide range of phenolic acids and flavonol glycosides in English and black walnuts (Table 1). English walnut are known to contain non-flavonoid phenolics including

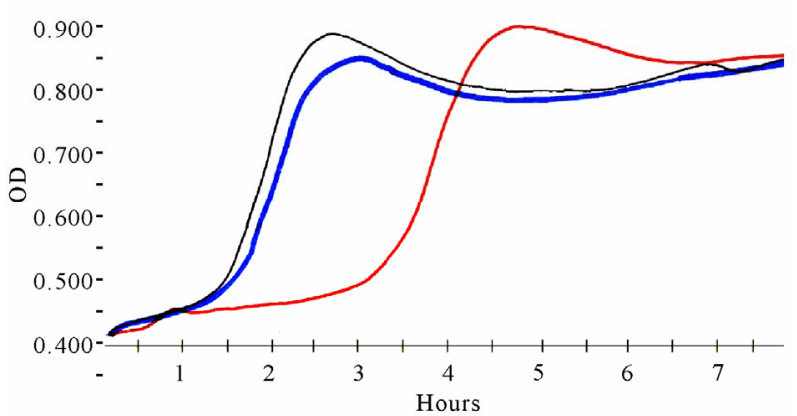

Figure 2. Representative oxidative lag-time curves (A234) for LDL oxidized by $5 \mu \mathrm{M}$ cupric ion in the absence of walnut (control) and in the presence of English or black walnut extracts. English walnut extracts greatly increased lag-time and yielded resistance to oxidation.

ellagic acid, valoneic acid dilactone and pedunculagin and have been reported to contain a single $433 \mathrm{MW}$ flavonol pentoside [6-11]. In the present study the total English walnut flavonol glycoside yields for $80 \%$ acetone and $80 \%$ methanol were 166 and $148 \mu \mathrm{g} / \mathrm{g}$ wet weight. In contrast, black walnuts contained a reduced amount of total flavonol-glycosides, with 24 and $4 \mu \mathrm{g} / \mathrm{g}$ with acetone and methanol, respectively. The flavonol glycoside profile of black walnut flesh had not been previously studied prior to this investigation.

English walnut leaves, in comparison to nuts, have been found to contain 3- and 5-caffeoylquinic acids, 3- and 4p-coumaroylquinic acids, p-coumaric acid, quercetin 3galactoside, quercetin 3-pentoside derivative, quercetin 3-arabinoside, quercetin 3-xyloside and quercetin 3-rhamnoside with HPLC/DAD in quantities ranging from 0.8 to $21 \mu \mathrm{g} / \mathrm{g}$ dry weight for $\mathrm{p}$-coumaric acid and quercetin3 -galactoside, respectively [12]. Given the difference between the wet and dry weight measures, the quantitative values are consistent to those previously observed [12]. The difference between English and black walnut profiles may be a reflection of the structure of the whole nut. Walnut anatomy consists of the shell, pellicle and nutmeat. The pellicle contains many antioxidant compounds that serve to protect the meat, which is high in unsaturated fat, from oxidation. English walnut nutmeat with pellicle contains $6.5 \mathrm{mmol}$ TAC per serving while the nutmeat alone contains 0.3 mmol TAC per serving [1]. English walnuts are bred to have a thin shell and husk for easier harvesting, making the pellicle more important in protecting the meat from rancidity. Black walnut anatomy consists of a thick husk, liquid layer, and strong shell. The added protective measures of the thick husk, liquid and strong shell may reduce the need for antioxidants in the form of phenolics to protect the nutmeat and germ DNA.

The lower phenolic profile content associated with black walnuts is suggestive of a reduced potential to pro- 

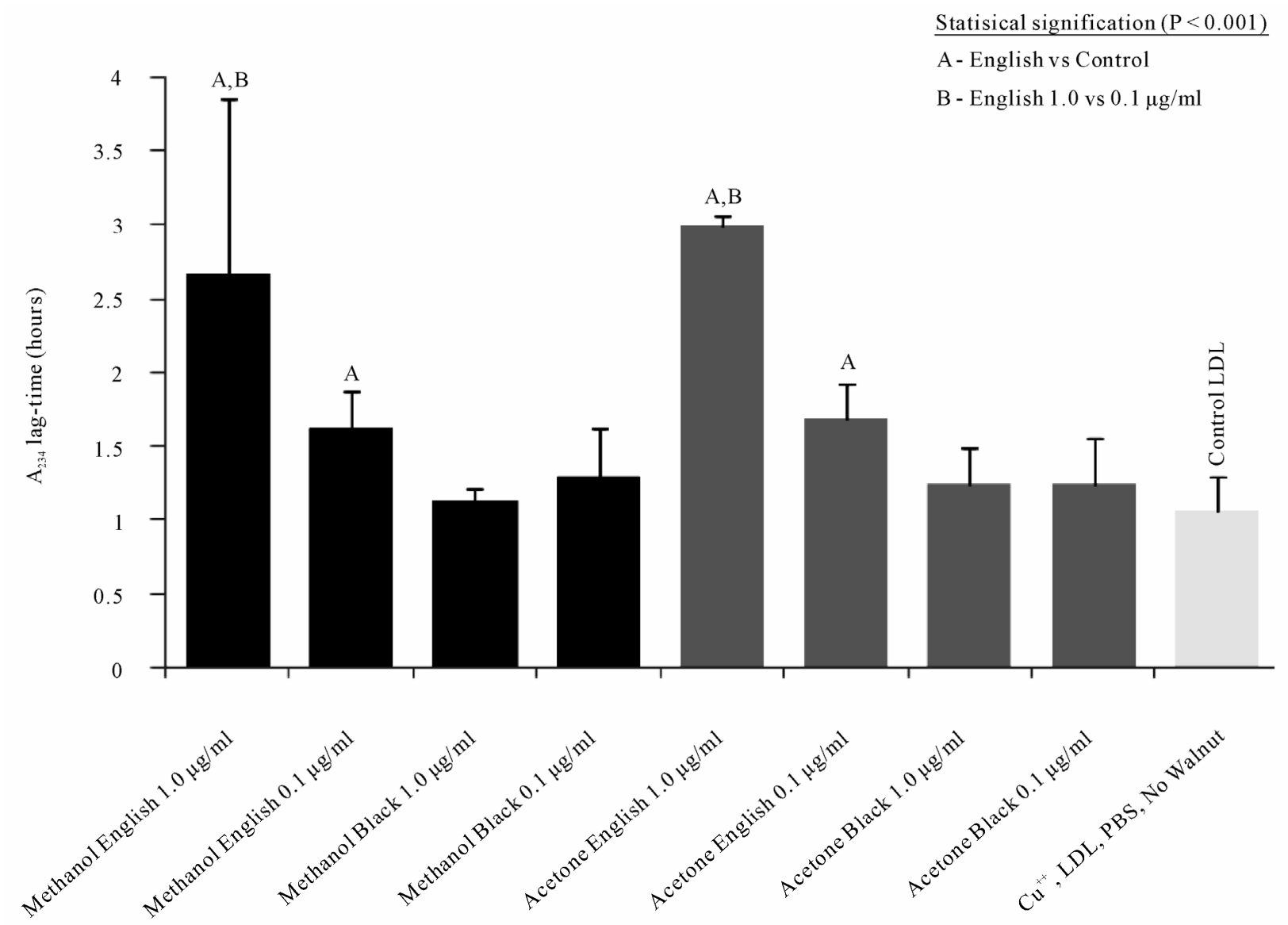

Figure 3. English walnut phenolic extracts at 1.0 and $0.1 \mu \mathrm{g} / \mathrm{mL}$ extended the lag-time for LDL oxidation by $5 \mu \mathrm{M}$ Cu++, while black walnut extracts failed to significantly delay the LDL oxidation lag-time.

vide human health benefits. In vitro analysis of Englishwalnut acetone and methanol extracts demonstrate suppression of cupricion mediated oxidation of LDL at 1.0 and $0.1 \mu \mathrm{g} / \mathrm{ml}$ concentrations (Figure 3). However, black walnut acetone and methanol extracts contained 7- and 36-fold less total flavonol glycosides, respectively, and were found to have non-significant increases in oxidative lag-time. While the TBARS test demonstrated that black walnut extracts have antioxidant activity, the activity and phenolic content was less than that of the English walnut extracts.

In contrast to the robust in vitro antioxidant effects found with English walnuts in the present study, walnut consumption did not significantly improve LDL protecttion ex vivo. Several studies have demonstrated that walnut consumption can improve human antioxidant capacity, however, others have failed to demonstrate that human consumption of English walnuts improved antioxidant capacity $[17,21,22]$. Plant phenolics have been shown to adhere to LDL resulting in improved antioxidant capacities following consumption [23]. However, because the
LDL samples were dialyzed prior to oxidation to remove EDTA, it is possible LDL samples were no longer associated with adherent dietary walnut phenolics. The reduced flavonol glycoside content of our black walnuts may also explain the results of our previous investigation which determined that human consumption of English walnuts is superior to black walnuts for improving the blood lipid profile and endothelial function [16].

The present study was designed to obtain preliminary data regarding the phenolic acid and flavonol contents of the walnuts used in antioxidant and human feeding trials. It was not designed to examine the effect of cultural effects nor growing location on walnut phenolic expression or antioxidant activity. In this regard the total leaf flavonol-glycoside content of six English walnut cultivars was found to be fairly uniform with a total phenolic content of $(70 \pm 3) \mu \mathrm{g} / \mathrm{g}$ wet weight [12]. A similarly tight standard deviation was observed for total phenolics in methanol extracts of English walnut kernel ((494 \pm 164$)$ $\mathrm{mg} / 100 \mathrm{~g}$ of kernel) and pellicle $((13,792 \pm 2917)$ $\mathrm{mg} / 100 \mathrm{~g}$ pellicle) in ten different English walnut cultivars 
[11]. Future studies may wish to examine differences within black walnut cultivars and growing locations. The 7 to 36 fold reductions in flavonol-glycoside content for black walnut suggest the effect would be independent of the specific black cultivar examined.

In the human trial of the present study a major limitation was lack of control over subject intake of other dietary elements that could have affected antioxidant status. While subjects reported no major changes in food or supplement intakes over the course of walnut consumption [16], there was no confirmation of this or attempt to control intake of other foods that may affect LDL oxidation.

\section{Conclusions}

English walnuts contain a greater content of phenolic acids and flavonols than black walnuts. Walnut flanonols included 5-caffeoylquinic acid, 3-caffeoylquinic acid (black walnut only), 4-caffeoylquinic acid, quercetin-3rutinoside, quercetin-3-galactoside, quercetin- 3-pentoside, quercetin-3-arabinoside, quercetin-3-rhamnoside, and the aglycone quercetin (English walnut only). The greater flavonol content of English may be responsible for its improved ability to protect LDL against oxidation in vitro. A 28 day period of English or black walnut consumption ( $30 \mathrm{~g}$ /day) was not sufficient to alter in vivo LDL antioxidant capacity. Further studies would be needed to confirm these effects across diets and nut sources.

\section{Acknowledgements}

The authors are also grateful to Mr. Graham Gibson (Applied Biosystems) for his gift of the API-3000 LC-MSMS instrument used in this study.

\section{REFERENCES}

[1] R. Bloomhoff, M. Carlsen, L. F. Andersen and D. R. Jacobs, "Health Benefits of Nuts: Potential Role of Antioxidants," British Journal of Nutrition, Vol. 96, No. 2 (Supplement), 2006, pp. S52-60. doi:10.1017/BJN20061864

[2] P. M. Kris-Etherton, F. B. Hu, E. Ros and J. Sabate, "The Role of Tree Nuts and Peanuts in the Prevention of Coronary Heart Disease: Multiple Potential Mechanisms," Journal of Nutrition, Vol. 138, No. 9, 2008, pp. 1746S1751S.

[3] D. Mozaffarian, R. Micha, and S. Wallace, "Effects on Coronary Heart Disease of Increasing Polyunsaturated Fat in Place of Saturated Fat: A Systematic Review and Metaanalysis of Randomized Controlled Trials," PLoS Medicine, Vol. 7, No. 3, 2010, Article ID e1000252. doi:10.1371/journal.pmed.1000252

[4] Food and Agriculture Organization of the United Nations, "World Crop Production 2008," 2011. http://faostat.fao.org/site/567/DesktopDefault.aspx?PageI $\underline{\mathrm{D}=567}$
[5] United States Department of Agriculture, "Total Acres of English Walnuts: 2007," 2009.

http://www.agcensus.usda.gov/

[6] L. Jurd, "Plant Polyphenols I. The Polyphenolic Constituents of the Pellicle of the Walnut (Juglans regia)," Journal of American Chemical Society, Vol. 78, No. 14, 1956, pp. 3445-3448. doi:10.1021/ja01595a050

[7] L. Jurd, "Plant Polyphenols II. The Benzylation of Ellagic Acid," Journal of American Chemical Society, Vol. 79, No. 22, 1957, pp. 6043-6047. doi:10.1021/ja01579a054

[8] L. Jurd, "Plant Polyphenols III. The Isolation of a New Ellagitannin from the Pellicle of the Walnut," Journal of American Chemical Society, Vol. 80, No. 9, 1958, pp. 2249-2252. doi:10.1021/ja01542a052

[9] K. J. Anderson, S. S. Teuber, A. Gobeille, P. Cremin, A. L. Waterhouse and F. M. Steinberg, "Walnut Polyphenolics Inhibit in Vitro Human Plasma and LDL Oxidation," Journal of Nutrition, Vol. 131, No. 11, 2001, pp. 2837 2842.

[10] T. Fukuda, H. Ito and T. Yoshida, "Antioxidative Polyphenols from Walnuts (Juglans Regia L.)," Phytochemistry, Vol. 63, No. 7, 2003, pp. 795-801. doi:10.1016/S0031-9422(03)00333-9

[11] M. Colaric, R. Veberic, A. Solar, M. Hudina and F. Stampar, "Phenolic Acids, Syringaldehyde, and Juglone in Fruits of Different Cultivars of Juglans Regia L," Journal of Agricultural and Food Chemistry, Vol. 10, No. 53, 2005, pp. 6390-6396. doi:10.1021/jf050721n

[12] J. A. Pereira, I. Oliveira, A. Sousa, P. Valentão, P. B. Andrade, I. C. Ferreira, F. Ferreres, A. Bento, R. Seabra and L. Estivinho, "Walnut (Juglans Regia L.) Leaves: Phenolic Compounds, Antibacterial Activity and Antioxidant Potential of Different Cultivars," Journal of Food Chemistry and Toxicology, Vol. 45, No. 11, 2007, pp. 2287-2295. doi:10.1016/j.fct.2007.06.004

[13] S. Torabian, E. Haddad, S. Rajaram, J. Banta and J. Sabate, "Acute Effect of Nut Consumption on Plasma Total Polyphenols, Antioxidant Capacity and Lipid Peroxidation," Journal of Human Nutrition and Diet, Vol. 22, No. 1, 2009, pp. 64-67. doi:10.1111/j.1365-277X.2008.00923.x

[14] D. K. Banel and F. B. Hu, "Effects of Walnut Consumption on Blood Lipids and Other Cardiovascular Risk Factors: A Meta-Analysis and Systematic Review," American Journal of Clinical Nutrition, Vol. 90, No. 1, 2009, pp. 56-63. doi:10.3945/ajen.2009.27457

[15] L. Calpe-Berdiel, J. C. Escolà-Gil and F. Blanco-Vaca, "New Insights into the Molecular Actions of Plant Sterols and Stanols in Cholesterol Metabolism," Atherosclerosis, Vol. 203, No. 1, 2009, pp. 18-31. doi:10.1016/j.atherosclerosis.2008.06.026

[16] P. Fitschen, K. Rolfhus, M. Winfrey, B. Allen, M. Manzy and M. Maher. "Cardiovascular Effects of Black Versus English Walnut Consumption," Journal of Medicinal Food, In Press, 2011. doi:10.1089/jmf.2010.0169

[17] Y. Ma, V. Y. Njike, J. Millet, S. Dutta, K. Doughty, J. A. Treu and D. L. Katz, "Effects of Walnut Consumption on 
Endothelial Function in Type 2 Diabetic Subjects: A Randomized Controlled Crossover Trial," Diabetes Care. Vol. 33, No. 2, 2010, pp. 227-232. doi:10.2337/dc09-1156

[18] D. Zambon, J. Sabate, S. Munoz, B. Campero, E. Casals, M. Merlos, J. C. Laguna and E. Ros, "Substituting Walnuts for Monounsaturated Fat Improves the Serum Lipid Profile of Hypercholesterolemic Men and Women. A Randomized Crossover Trial," Annals of Internal Medicine, Vol. 132, No. 7, 2000, pp. 538-546.

[19] A. P. Singh, T. Wilson, A. J. Kalk, J. Cheong and N. Vorsa, "Isolation of Specific Cranberry Flavonoids for Biological Activity Assessment," Food Chemistry, Vol. 116, No. 4, 2009, pp. 963-968. doi:10.1016/j.foodchem.2009.03.062

[20] T. Wilson, H. March, W. J. Banz, S. Adler, C. Y. Meyers, T. A.Winters and M. A. Maher, "Antioxidant Effects of Phyto- and Synthetic-Esterogens on $\mathrm{Cu}^{++}$-induced Oxidation of Low-Density Lipoprotein in Vitro," Life Sciences, Vol. 70, No. 19, 2002, pp. 2287-2297.
doi:10.1016/S0024-3205(02)01483-2

[21] D. L. McKay, C. Y. Chen, K. J. Yeum, N. R. Matthan, A. H. Lichtenstein and J. B. Blumberg, "Chronic and Acute Effects of Walnuts on Antioxidant Capacity and Nutritional Status in Humans: A Randomized, Cross-over Pilot Study," Nutrition Journal, Vol. 12, No. 9, 2010, p. 21. doi:10.1186/1475-2891-9-21

[22] E. Ros, I. Nunez, A. Perez-Heras, M. Serra, R. Gilabert, E. Casals and R. Deulofeu, "A Walnut Diet Improves Endothelial Function in Hypercholesterolemic Subjects: A Randomized Crossover Trial," Circulation, Vol. 109, No. 13, 2004, pp. 1609-1614. doi:10.1161/01.CIR.0000124477.91474.FF

[23] V. Ivanov, A. C. Carr and B. Frei, "Red Wine Antioxidants Bind to Human Lipoproteins and Protect Them from Metal Ion-Dependent and -Independent Oxidation," Journal of Agricultural and Food Chemistry, Vol. 49, No. 9, 2001, pp. 4442-4449. doi:10.1021/jf010117m 